\title{
春季低温对小麦花粉育性及粒数形成的影响
}

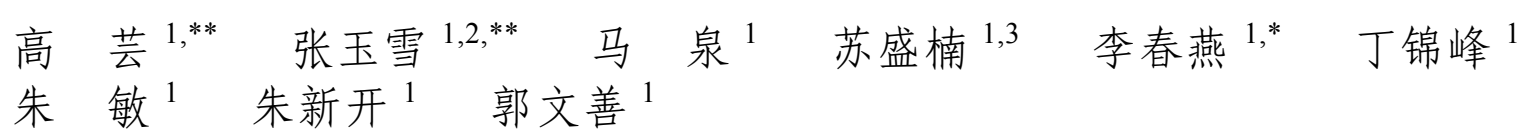

1 扬州大学江苏省作物遗传生理国家重点实验室培育点 / 粮食作物现代产业技术协同创新中心, 江苏扬州 $225009 ;^{2}$ 太仓市农业机 械技术推广站, 江苏太仓 $215499 ;^{3}$ 太仓市城厢镇农业技术服务站, 江苏太仓 215499

摘 要: 小麦拔节后遭遇春季低温, 每穗粒数下降, 产量降低。为探明春季低温引起每穗粒数减少的生理原因, 以春 性小麦扬麦 16 和半冬性小麦徐麦 30 为供试品种, 研究小麦倒二叶出生期 $\left(\right.$ 昼夜 $5^{\circ} \mathrm{C} /-3^{\circ} \mathrm{C}$ )、孕穗期 $\left(\right.$ 昼夜 $\left.8^{\circ} \mathrm{C} /-1^{\circ} \mathrm{C}\right)$ 和 开花期(昼夜 $12^{\circ} \mathrm{C} / 4^{\circ} \mathrm{C}$ )分别进行低温处理对小麦花粉育性及每穗粒数形成的影响。结果表明: 倒二叶出生期和孕穗期 低温均导致 2 个小麦品种在二胞花粉期和三胞花粉期花药中的多糖物质淀粉和蛋白质的代谢异常, 线毛层解体延迟; 孕穗期低温还造成花粉母细胞减数分裂中染色体配对异常、出现微核等情况, 影响正常雄配子体形成; 花粉败育率表 现为倒二叶出生期低温处理 $>$ 孕穗期低温处理 $>$ 开花期低温处理, 徐麦 30 败育率高于扬麦 $16 ; 3$ 个时期低温均显著降 低了 2 个小麦品种结实小穗数、每小穗结实粒数和每穗粒数, 以倒二叶出生期低温处理穗粒数降低的幅度最大。相 关分析表明, 春季低温引起花粉母细胞减数分裂异常、线毛层延迟解体、花药营养物质供给不足导致的花粉育性下 降, 是春季低温导致小麦每穗粒数减少的主要原因。

关键词: 小麦; 低温; 粒数; 花粉育性

\section{Effects of low temperature in spring on fertility of pollen and formation of grain number in wheat}

GAO Yun ${ }^{1, * *}$, ZHANG Yu-Xue ${ }^{1,2, * *}$, MA Quan ${ }^{1}$, SU Sheng-Nan ${ }^{1,3}$, LI Chun-Yan ${ }^{1, *}$, DING Jin-Feng ${ }^{1}$, ZHU Min $^{1}$, ZHU Xin-Kai ${ }^{1}$, and GUO Wen-Shan ${ }^{1}$

\footnotetext{
${ }^{1}$ Jiangsu National Key Laboratory Nurturing Center of Crop Genetics and Physiology / Co-Innovation Center for Modern Production Technology of Grain Crops, Yangzhou University, Yangzhou 225009, Jiangsu, China; ${ }^{2}$ Taicang Agricultural Machinery Technology Promotion Station, Taicang 215499, Jiangsu, China; ${ }^{3}$ Taicang Chengxiang Agricultural Technology Service Station, Taicang 215499, Jiangsu, China
}

\begin{abstract}
Grain yield and the number of grains per ear of wheat decreased under the low temperature after jointing stage. In order to explore the physiological reasons of the decrease of grains number per ear by low temperature in spring, the spring wheat variety Yangmai 16 and the semi-winter wheat variety Xumai 30 were used as tested varieties to analyze the effects of low temperature in spring on the fertility of pollen and the formation of grain numbers at the appearance of the penultimate leaf stage $\left(5^{\circ} \mathrm{C} /-3^{\circ} \mathrm{C}\right.$, day/night), booting stage $\left(8^{\circ} \mathrm{C} /-1^{\circ} \mathrm{C}\right.$, day/night), and anthesis stage $\left(12^{\circ} \mathrm{C} / 4^{\circ} \mathrm{C}\right.$, day/night). The results showed that low temperature at the appearance of the penultimate leaf stage and booting stage resulted in abnormal metabolism of starch and protein in the anther both at the binuclear and tri-nuclear pollen stages and delayed degradation of the tapetum. The low temperature at the booting stage caused abnormal meiosis of pollen mother cells, abnormalities in chromosome pairing, which affected the
\end{abstract}

\footnotetext{
本研究由国家重点研发计划项目(2018YFD0300802, 2016YFD0300107), 国家自然科学基金项目(31771711), 扬州市优秀青年基金项目 (YZ2017098), 江苏省自主创新专项(CX(18)1002)和江苏高校优势学科建设工程项目资助。

The study was supported by the National Key Research and Development Program of China (2018YFD0300802, 2016YFD0300107), the National Natural Science Foundation of China (31771711), the Yangzhou Science Foundation for Excellent Youths (YZ2017098), the Funds for Creative Research of Jiangsu Province (CX(18)1002), and the Priority Academic Program Development of Jiangsu Higher Education Institutions.
}

*通信作者(Corresponding author): 李春燕, E-mail: licy@yzu.edu.cn

** 同等贡献(Contributed equally to this work)

第一作者联系方式: 高芸, E-mail: 307057893@qq.com

Received (收稿日期): 2020-04-05; Accepted (接受日期): 2020-08-19; Published online (网络出版日期): 2020-09-10.

URL: https://kns.cnki.net/kcms/detail/11.1809.S.20200909.1432.008.html 
formation of male gametophyte. The abortion rate of pollen was more significantly increased under low temperature at the appearance of the penultimate leaf stage than that at the booting stage, and it was the minimum at anthesis stage. The abortion rate of pollen in Xumai 30 was higher than that in Yangmai 16. The low temperature at three stages had significant effects on the number of spikelets, the number of fertile spikelets and the number of grains per spikelet. The effect of low temperature at the appearance of the penultimate leaf stage on grains number per spikelet was the most significant. There was a significant positive correlation between the number of grains per spike and pollen fertility, which was affected by abnormal meiosis, delayed degradation of the tapetum, and undersupply of nutriment for anther development. Therefore, the decline of pollen fertility caused by low temperature in spring is the main reason for the decrease of grains number per spike.

Keywords: wheat; cold stress; grain number; pollen fertility

温度是影响小麦生长发育的重要环境因素之 一, 特别是春季 $3 、 4$ 月低温, 小麦正处于拔节、 孕穗和开花的关键生育时期, 低温严重影响了小 麦等农作物的生长 ${ }^{[1-3]}$ 。我国黄淮平原冬麦区河南 省和山东省霜冻害一般发生频率达 $30 \%$ 以上, 最 高年份可达 $70 \%{ }^{[4]}$ 。2 016 年越冬冻害造成河南省 柘城县小麦减产 $5 \%$ 20\%, 早春冻害造成减产

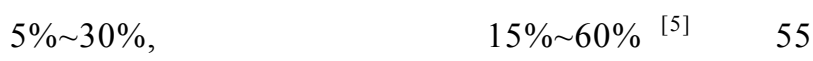
年来, 江苏省倒春寒平均每年发生 3.8 次, 每次平 均持续时间为 $3.2 \mathrm{~d}$, 中级以上倒春寒一般发生率 达 $22 \%$ 以上 ${ }^{[6]}$ 。2 2013 年 3 月江苏省出现 4 次寒潮 和温度急剧下降的恶劣天气, $24 \mathrm{~h}$ 降温幅度高达 $21.2^{\circ} \mathrm{C}$, 最低温度 $-0.7^{\circ} \mathrm{C}$, 受灾严重地区兴化市小 麦平均减产 $25 \%$ 左右 ${ }^{[7]}$, 可见春季低温是制约小 麦生产的重要气候因素。

小麦生育中后期逆境胁迫会造成小麦每穗粒数 和千粒重显著下降, 制约小麦产量的形成 ${ }^{[8-9]}$, 小麦 在药隔形成期和孕穗期遇到低温影响更加显著, 每 穗粒数的减少与温度的降幅和低温持续时间成正 比 $^{[10-11]}$; 尤其是减数分裂期是小麦低温最敏感的时 期, 该时段低温胁迫致每穗粒数减少是产量下降的 主要原因 ${ }^{[12]}$ 。

小麦幼穗发育的好坏决定了穗型的大小, 其发 育过程受到外界温度的影响 ${ }^{[13-14]}$, 而粒数的多少往 往与花粉育性和花后灌浆物质多少有关。导致小麦 花粉育性降低的原因很多: 低温条件下小麦花粉母 细胞减数分裂过程中出现非同源染色体配对的异常 现象, 导致花粉败育 ${ }^{[12]}$; 低温胁迫下植物体内活性 氧过度积累, 花药抗氧化酶活性降低是导致小麦花 药败育的又一原因 ${ }^{[15-17]}$; 在不育系小麦方面的研究 表明, 线毡层程序化死亡过程的异常、花粉壁无法 正常合成、以及花药中小孢子母细胞淀粉和脂类物 质代谢异常等是温敏核不育小麦受温度影响致花粉 败育的主要原因 ${ }^{[18-20]}$ 。

一定强度的春季低温显著降低了小麦产量, 除
穗数减少外, 每穗粒数下降也是减产的重要原因之 一。但导致小麦粒数下降的原因是小孢子母细胞减 数分裂的异常, 还是因为花药中营养物质代谢、线 毡层死亡过程的异常引起的花粉败育, 尚没有明确 的结论。本试验以春性小麦品种扬麦 16 和半冬性小 麦品种徐麦 30 为材料, 在小麦倒二叶出生期、孕穗 期和开花期分别进行低温处理, 研究春季低温对小 麦花粉育性和粒数形成的影响及其生理机制, 为提 高小麦抗低温能力、确保小麦稳产提供理论依据和 技术支持。

\section{1 材料与方法}

供试品种为春性品种扬麦 16 和半冬性品种徐 麦 30, 试验于 2015-2017 年在扬州大学江苏省作 物遗传生理实验室盆钵试验场进行。试验用土为轻 壤土, 两年度有机质含量平均为 $14.61 \mathrm{~g} \mathrm{~kg}^{-1}$, 碱解 氮含量为 $52.35 \mathrm{~g} \mathrm{~kg}^{-1}$, 速效磷含量为 $37.35 \mathrm{~g} \mathrm{~kg}^{-1}$, 速效钾含量为 $96.51 \mathrm{~g} \mathrm{~kg}^{-1}$ 。采用盆栽种植, 盆钵高 $26 \mathrm{~cm}$, 上口直径 $26 \mathrm{~cm}$, 底面直径 $18 \mathrm{~cm}$, 底部一 共 8 个排水孔。每盆装土 $12 \mathrm{~kg}$, 基施尿素 $0.85 \mathrm{~g}$ 及复合肥 $\left(15 \% \mathrm{~N} 、 15 \% \mathrm{P}_{2} \mathrm{O}_{5}\right.$ 和 $\left.15 \% \mathrm{~K}_{2} \mathrm{O}\right) 3.5 \mathrm{~g}$, 浇 等量水自然沉实后播种, 覆土 $1 \mathrm{~kg}$ 。四叶期追施壮 蒒集肥, 每盆施尿素 $0.35 \mathrm{~g}$; 叶龄余数 2.5 时追施拔节 肥, 每盆施尿素 $0.4 \mathrm{~g}$ 和复合肥 $3.33 \mathrm{~g}$ 。2015 年于 10 月 31 日播种, 2016 年于 11 月 18 日播种, 每盆播 种 12 粒, 四叶期定苗, 每盆留生长一致植株 8 株。 在人工智能控温室中进行低温处理(温度误差 $\pm 0.5^{\circ} \mathrm{C}$, 大气相对湿度 $70 \%$, 光量子通量密度 $\left.800 \mu \mathrm{mol} \mathrm{m}^{-2} \mathrm{~s}^{-1}\right)$ 。

\section{1 试验设计}

于倒二叶出生期(倒二叶露尖 $1 \sim 2 \mathrm{~cm}$ )、孕穗期 (剑叶全展, 剑叶与倒二叶叶枕距 2 4 cm) 和开花期 (小麦中部小穗开出 1 2 朵小花)选取生长一致的盆 钵分别进行低温处理。倒二叶出生期、孕穗期、开 花期昼夜低温分别为 $5^{\circ} \mathrm{C} /-3^{\circ} \mathrm{C} 、 8^{\circ} \mathrm{C} /-1{ }^{\circ} \mathrm{C}$ 和 
$12^{\circ} \mathrm{C} / 4^{\circ} \mathrm{C}$ 。每个处理时间均设 $24 \mathrm{~h}$ 和 $48 \mathrm{~h}$ 两个水平, 盆钵土壤水分为田间持水量的 $60 \%$ \% $70 \%$, 处理结束 后移至自然条件下生长至成熟，以室外自然生长的 植株为对照。

\section{2 测定内容与方法}

1.2 .1 花粉母细胞减数分裂观察 取处于减数分 裂期的麦穗(剑叶与倒二叶叶枕距为 $3 \sim 4 \mathrm{~cm}$ )中下部 花药, 用卡诺固定液固定, 置 $-20^{\circ} \mathrm{C}$ 冰箱保存。试验 时将花药取出, 置于载玻片上, 加少许醋酸洋红, 用解剖针迅速将花药捣碎, 盖上盖玻片, 在酒精灯 上烤一下, 在显微镜下观察, 挑选适期的花粉母细 胞。在盖玻片一侧加入适量的 $45 \%$ 醋酸, 在另一侧 放入吸水纸置换出染液, 使细胞质背景颜色变浅。 在液氮中放置数秒(直到声音变弱), 用刀片迅速揭 去盖玻片, 晾干。滴加 4\%多聚甲醛 $500 \mu \mathrm{L}$ 静置 5 $\min$, 分别用 $70 \% 、 90 \%$ 和 $100 \%$ 酒精脱水。滴加 DAPI10 $\mu \mathrm{L}$, 盖上盖玻片, 压片, 苂光显微镜 (Olympus BX60)放大倍数为 100 倍进行观察, 使用 Olympus cellSens Dimension 软件照相。

1.2.2 花药细胞化学观察花药细胞化学观察方

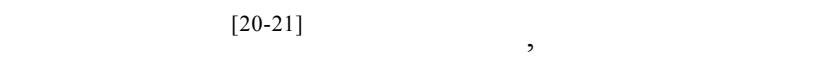
药, 一半花药通过醋酸洋红压片确定二核期和三核 期, 另一半用 $0.1 \mathrm{~mol} \mathrm{~L}^{-1}(\mathrm{pH} 7.4$ ) 磷酸盐缓冲液配置 的含 $3 \%$ 戊二醛固定液 $4{ }^{\circ} \mathrm{C}$ 固定 $8 \mathrm{~h}$, 再用磷酸缓冲液 漂洗 3 次, 乙醇逐级脱水。用 LR White 树脂渗透、 包埋、聚合。选用 Leica EM UC7 型(德国)超薄切片 机切 $1.2 \mu \mathrm{m}$ 的半薄切片, 高碘酸-希夫反应鉴别红 色多糖物质, 考马斯亮蓝 R-250 鉴别蓝色蛋白质类 物质, 利用 Leica DM 2500 型(德国)正置生物显微镜 进行观察。

\section{2 .3 花粉活性观察 于开花期取麦穗中下部花}

药, 采用 $\mathrm{I}_{2}-\mathrm{KI}$ 染色制片, 采用蔡司显微镜(Axio Imager D2 型)观察花粉发育情况, 统计花粉败育率。

1.2.4 穗部性状调查于成熟期每个处理取 5 盆, 调查每个处理每穗结实小穗数、退化小穗数、每小 穗结实粒数和每穗粒数。

\section{3 数据分析}

本文数据采用 Microsoft Excel 2010、DPS 6.55 等软件进行数据的计算、绘图、统计分析。因 2015-2017 两年度小麦生长季各项指标变化趋势 基本一致, 本文重点以 2016-2017 年数据进行详 细分析。

\section{2 结果与分析}

2.1 春季不同时期低温对小麦花粉育性的影响

2.1 .1 孕穗期低温对小麦花粉母细胞减数分裂的影 响 与自然生长对照小麦花粉母细胞减数分裂后 期 I、末期 I 和末期 II 相比较(图 1-1 3), 孕穗期 $8^{\circ} \mathrm{C} /-1^{\circ} \mathrm{C}$ 低温处理 $48 \mathrm{~h}, 2$ 个品种小麦花粉母细胞减 数分裂过程均观察到减数分裂异常情况。扬麦 16 花 粉母细胞减数分裂后期 I 出现多条落后染色体, 组 成染色体桥(图 1-4); 在末期 I 子细胞染色体排列散 乱, 细胞周围出现微核(图 1-5); 在末期 II 细胞周围 出现微核(图 1-6)。徐麦 30 花粉母细胞减数分裂期 后期 I 出现染色体桥和落后染色体(图 1-7，8); 在末 期 II 出现大小不一致的子细胞(图 1-9), 表明孕穗期 低温影响小麦花粉母细胞的减数分裂过程。

\subsection{2 春季不同时期低温对小麦花药发育的影响}

自然生长的 2 个品种小麦花药中, 大液泡减小 或者消失, 细胞质内含物积累正常, 在二胞花粉期, 多糖物质淀粉和蛋白质含量逐渐增加(图 2-A, D 和 图 4-A, D); 在三胞花粉期, 线毛层降解情况较好, 少有残留的痕迹(图 3-A, D 和图 5-A, D); 在小麦倒 二叶出生期和孕穗期低温处理 $48 \mathrm{~h}$ 后, 处在二胞花 粉期的花药, 大液泡分解程度较低, 细胞质内含物 未增加, 颗粒物较少, 淀粉和蛋白质积累量低, 形 似空壳, 花粉细胞出现较多不规则的畸形状态(图 2-B, C, E, F 和图 4-B, C, E, F); 三胞花粉期线毡层细 胞明显延迟分解, 有较多残留(图 3-B, C, E, F 和图 $5-\mathrm{B}, \mathrm{C}, \mathrm{E}, \mathrm{F})$ 。倒二叶出生期低温处理后小麦花药中 淀粉和蛋白质的积累量均低于孕穗期低温处理, 淀 粉和蛋白质代谢异常的现象更显著(图 3 和图 5)。 这些结果说明倒二叶出生期和孕穗期低温胁迫均会 导致花药中淀粉、蛋白质代谢异常和线毡层降解延 迟, 影响了小麦花粉的正常发育。2 个品种均表现为 倒二叶出生期低温处理对花药淀粉和蛋白质代谢的 影响程度大于孕穗期低温处理。

2.1.3 春季不同时期低温对小麦花粉粒活性的影响 开花期通过碘染色观察花粉粒活性, 扬麦 16 和 徐麦 30 在倒二叶出生期低温处理后败育率最高, 变 化范围在 $23.6 \%$ 29.6\%, 其次是孕穗期, 变化范围 在 $13.6 \% \sim 19.8 \%$, 开花期败育率仅为 $7.0 \% \sim 16.6 \%$ (表 1)。3 个时期低温处理后花粉粒败育率均表现为 徐麦 30 高于扬麦 16 , 并且随低温处理时间的延长败 育率增加。 

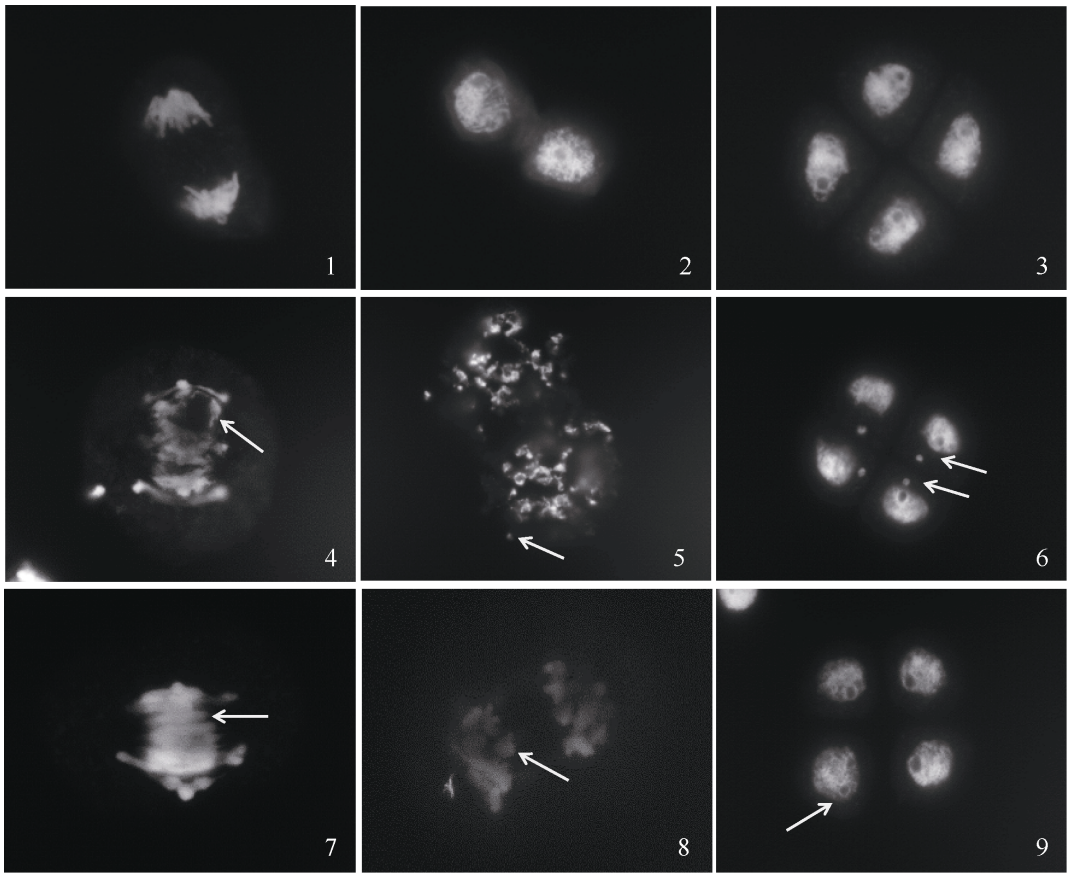

图 1 孕穗期低温处理 $48 \mathrm{~h}$ 对小麦花粉母细胞减数分裂的影响 $(100 \times)$

Fig. 1 Effects of low temperature treatment lasting for 48 hours at booting stage on the meiosis of wheat pollen mother cells (100 $\times)$ 1: 扬麦 16 对照后期 I; 2: 扬麦 16 对照末期 I; 3: 扬麦 16 对照末期 II; 4: 扬麦 16 后期 I (箭头示落后染色体); 5: 扬麦 16 末期 I (箭头示微核); 6: 扬麦 16 末期 II (箭头示微核); 7: 徐麦 30 后期 I (箭头示染色体桥); 8: 徐麦 30 后期 I (箭头示落后染色体); 9: 徐麦 30 末期 II (箭头示子细 胞大小不一致)。自然生长条件下, 两小麦品种花粉母细胞减数分裂过程基本一致, 本文用扬麦 16 自然生长的减数分裂图片为对照。

1: anaphase I of Yangmai 16 as the control; 2: telophase I of Yangmai 16 as the control; 3: telophase II of Yangmai 16 as the control; 4: anaphase I of Yangmai 16 (the arrow shows lagged chromosomes); 5: telophase I of Yangmai 16 (the arrow shows micronuclei); 6: telophase II of Yangmai 16 (the arrows show micronuclei); 7: anaphase I of Xumai 30 (the arrow shows chromosome bridge); 8: anaphase I of Xumai 30 (the arrow shows lagged chromosomes); 9: telophase II of Xumai 30 (the arrow shows different size cells). The meiosis of two wheat pollen mother cells was accordant, the pictures of meiosis of Yangmai 16 growing in the nature acted as the control.
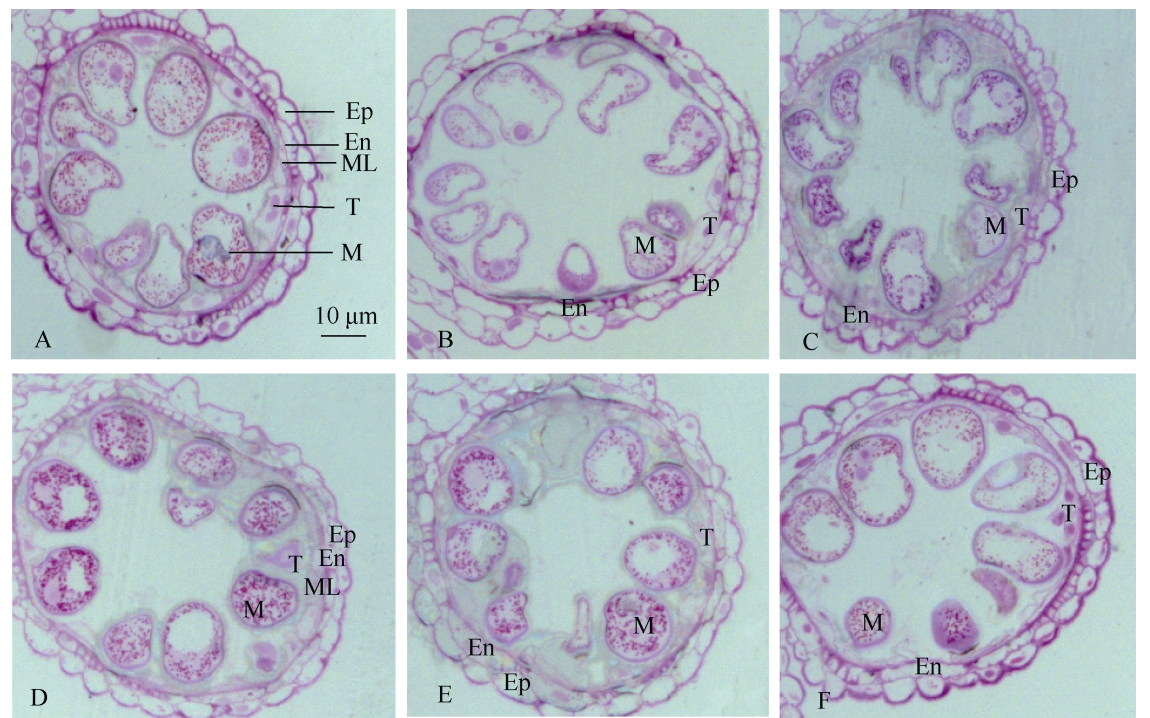

图 2 不同时期低温处理的小麦花药细胞化学观察(二胞花粉期淀粉染色)

Fig. 2 Cytochemical observations of wheat anthers treated with low temperature at different stages (starch staining at the binuclear pollen stage)

A: 扬麦 16 自然生长对照; B: 扬麦 16 倒二叶出生期低温处理 $48 \mathrm{~h} ; \mathrm{C}$ : 扬麦 16 孕穗期低温处理 $48 \mathrm{~h} ; \mathrm{D}:$ 徐麦 30 自然生长对照; E: 徐麦 30 倒二叶出生期低温处理 $48 \mathrm{~h}$; F: 徐麦 30 孕穗期低温处理 48 h; Ep: 表皮; En: 药室内壁; ML: 中层; M: 小孢子母细胞; P: 花粉; T: 线毛层。

A: Yangmai 16 in the natural environment; B: Yangmai 16 under low temperature treatment at the appearance of the penultimate leaf stage for 48 hours; C: Yangmai 16 under low temperature treatment at booting stage for 48 hours; D: Xumai 30 in the natural environment; E: Xumai 30 under low temperature treatment at the appearance of the penultimate leaf stage for 48 hours; F: Xumai 30 under low temperature treatment at booting stage for 48 hours; Ep: epidermis; En: endothecium; ML: middle layer; M: microspore mother cell; P: pollen; T: tapetum. 

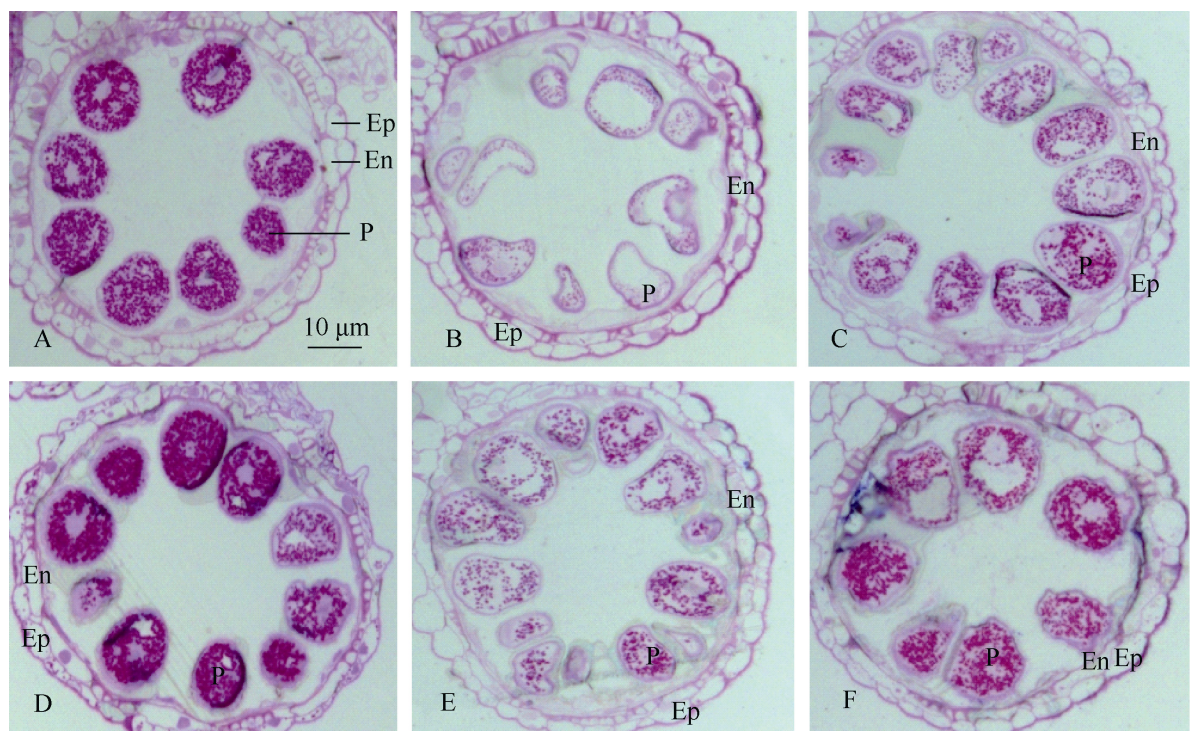

图 3 不同时期低温处理的小麦花药细胞化学观察(三胞花粉期淀粉染色)

Fig. 3 Cytochemical observations of wheat anthers treated with low temperature at different stages (starch staining at the tri-nuclear pollen stage)

A：扬麦 16 自然生长对照; B：扬麦 16 倒二叶出生期低温处理 $48 \mathrm{~h} ; \mathrm{C}$ ：扬麦 16 孕穗期低温处理 $48 \mathrm{~h}$; D: 徐麦 30 自然生长对照; E：徐 麦 30 倒二叶出生期低温处理 $48 \mathrm{~h} ; \mathrm{F}$ : 徐麦 30 孕穗期低温处理 $48 \mathrm{~h} ; \mathrm{Ep}$ : 表皮; En: 药室内壁; ML: 中层; M: 小孢子母细胞; P: 花粉; T: 线毡层。

A: Yangmai 16 in the natural environment; B: Yangmai 16 under low temperature treatment at the appearance of the penultimate leaf stage for 48 hours; C: Yangmai 16 under low temperature treatment at booting stage for 48 hours; D: Xumai 30 in the natural environment; E: Xumai 30 under low temperature treatment at the appearance of the penultimate leaf stage for 48 hours; F: Xumai 30 under low temperature treatment at booting stage for 48 hours; Ep: epidermis; En: endothecium; ML: middle layer; M: microspore mother cell; P: pollen; T: tapetum.
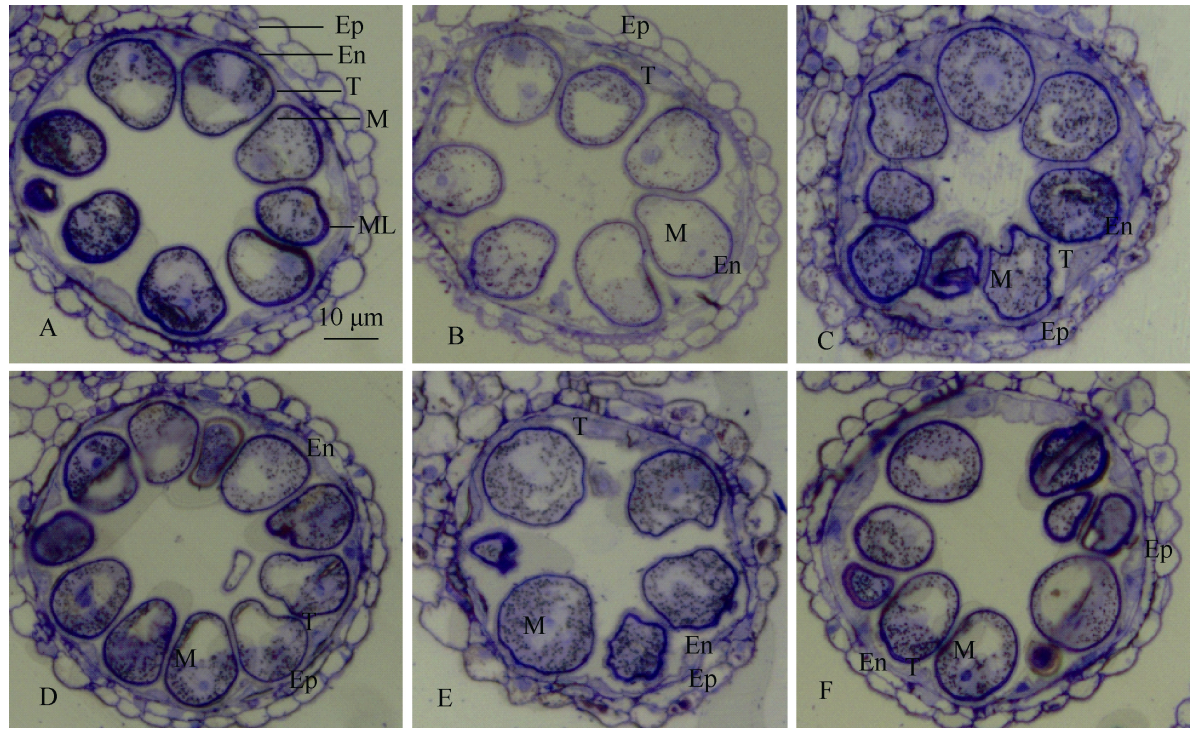

图 4 不同时期低温处理的小麦花药细胞化学观察(二胞花粉期蛋白染色)

Fig. 4 Cytochemical observations of wheat anthers treated with low temperature at different periods (protein staining at the binuclear pollen stage)

A：扬麦 16 自然生长对照; B：扬麦 16 倒二叶出生期低温处理 $48 \mathrm{~h} ; \mathrm{C}$ ：扬麦 16 孕穗期低温处理 $48 \mathrm{~h} ; \mathrm{D}$ : 徐麦 30 自然生长对照; E：徐 麦 30 倒二叶出生期低温处理 $48 \mathrm{~h} ; \mathrm{F}$ : 徐麦 30 孕穗期低温处理 $48 \mathrm{~h} ; \mathrm{Ep}$ : 表皮; En: 药室内壁; ML: 中层; M: 小孢子母细胞; P: 花粉; T: 线毡层。

A: Yangmai 16 in the natural environment; B: Yangmai 16 under low temperature treatment at the appearance of the penultimate leaf stage for 48 hours; C: Yangmai 16 under low temperature treatment at booting stage for 48 hours; D: Xumai 30 in the natural environment; E: Xumai 30 under low temperature treatment at the appearance of the penultimate leaf stage for 48 hours; F: Xumai 30 under low temperature treatment at booting stage for 48 hours; Ep: epidermis; En: endothecium; ML: middle layer; M: microspore mother cell; P: pollen; T: tapetum. 

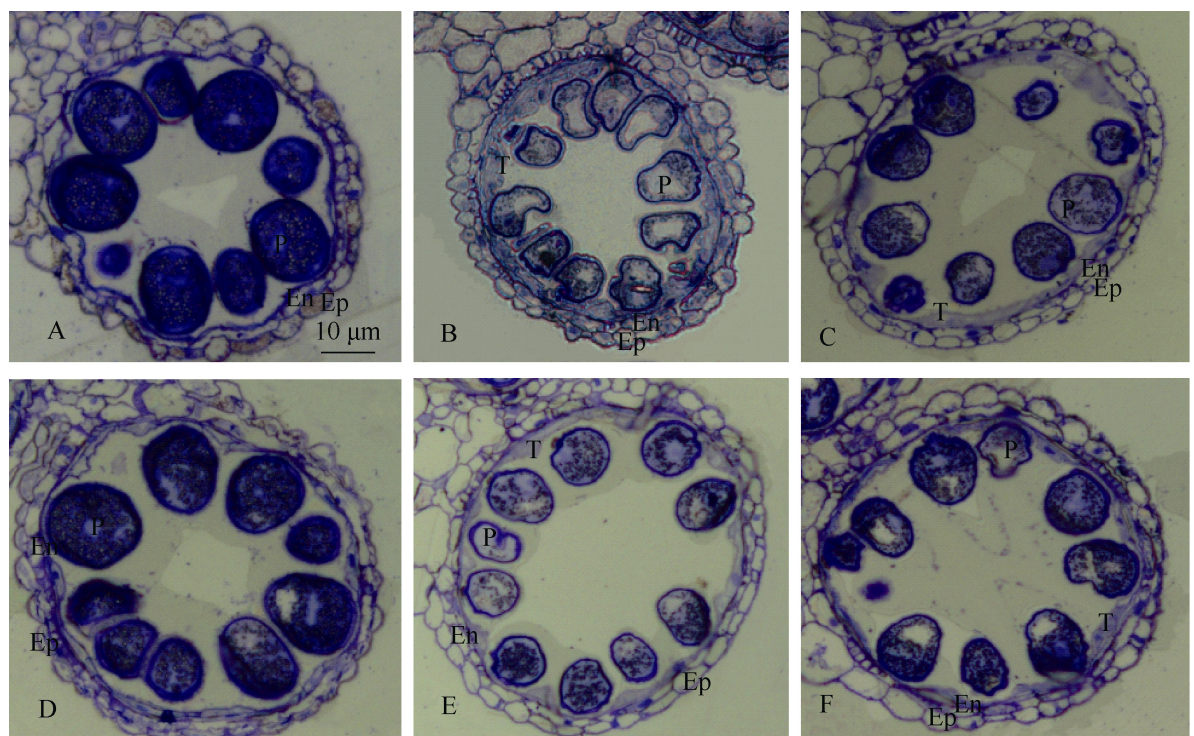

图 5 不同时期低温处理的小麦花药细胞化学观察(三胞花粉期蛋白染色)

Fig. 5 Cytochemical observations of wheat anthers treated with low temperature at different stages (protein staining at the tri-nuclear pollen stage)

A: 扬麦 16 自然生长对照; B: 扬麦 16 倒二叶出生期低温处理 $48 \mathrm{~h} ; \mathrm{C}$ : 扬麦 16 孕穗期低温处理 $48 \mathrm{~h} ; \mathrm{D}:$ 徐麦 30 自然生长对照; E: 徐麦 30 倒二叶出生期低温处理 $48 \mathrm{~h}$; F: 徐麦 30 孕穗期低温处理 48 h; Ep: 表皮; En: 药室内壁; ML: 中层; M: 小狍子母细胞; P: 花粉; T: 线毛层。

A: Yangmai 16 in the natural environment; B: Yangmai 16 under low temperature treatment at the appearance of the penultimate leaf stage for 48 hours; C: Yangmai 16 under low temperature treatment at booting stage for 48 hours; D: Xumai 30 in the natural environment; E: Xumai 30 under low temperature treatment at the appearance of the penultimate leaf stage for 48 hours; F: Xumai 30 under low temperature treatment at booting stage for 48 hours; Ep: epidermis; En: endothecium; ML: middle layer; M: microspore mother cell; P: pollen; T: tapetum.

表 1 春季不同时期低温对小麦花粉粒活性的影响

Table 1 Effects of low temperature in spring at different stages on wheat pollen activity

\begin{tabular}{|c|c|c|c|c|c|c|}
\hline \multirow{2}{*}{$\begin{array}{l}\text { 年度 } \\
\text { Year }\end{array}$} & \multirow{2}{*}{$\begin{array}{c}\text { 低温处理 } \\
\text { Low-temperature treatment }\end{array}$} & \multirow{2}{*}{$\begin{array}{l}\text { 处理时长 } \\
\text { Time (h) }\end{array}$} & \multicolumn{2}{|c|}{ 扬麦 16 Yangmai 16} & \multicolumn{2}{|c|}{ 徐麦 30 Xumai 30} \\
\hline & & & $\begin{array}{c}\text { 败育率 } \\
\text { Abortion rate (\%) }\end{array}$ & $\begin{array}{c}\text { 升幅 } \\
\text { Increase (\%) }\end{array}$ & $\begin{array}{c}\text { 败育率 } \\
\text { Abortion rate (\%) }\end{array}$ & $\begin{array}{c}\text { 升幅 } \\
\text { Increase }(\%)\end{array}$ \\
\hline \multirow[t]{8}{*}{$2015-2016$} & 倒二叶出生期 & 24 & $25.5 \mathrm{~b}$ & 18.6 & $26.2 \mathrm{~b}$ & 18.8 \\
\hline & $\begin{array}{l}\text { The appearance of the penultimate leaf } \\
\text { stage }\left(5^{\circ} \mathrm{C} /-3^{\circ} \mathrm{C}\right)\end{array}$ & 48 & $28.4 \mathrm{a}$ & 21.5 & $29.6 \mathrm{a}$ & 22.2 \\
\hline & 孕穗期 & 24 & $15.3 \mathrm{~d}$ & 8.5 & $17.5 \mathrm{~d}$ & 10.1 \\
\hline & Booting stage $\left(8^{\circ} \mathrm{C} /-1^{\circ} \mathrm{C}\right)$ & 48 & $19.2 \mathrm{c}$ & 12.3 & $19.8 \mathrm{c}$ & 12.4 \\
\hline & 开花期 ～～～～～～～～～～～ & 24 & $8.0 \mathrm{e}$ & 1.2 & $8.7 \mathrm{e}$ & 1.3 \\
\hline & Anthesis stage $\left(12^{\circ} \mathrm{C} / 4^{\circ} \mathrm{C}\right)$ & 48 & $13.7 \mathrm{~d}$ & 6.9 & $16.6 \mathrm{~d}$ & 9.2 \\
\hline & 自然生长对照 Control & & $6.8 \mathrm{e}$ & - & $7.4 \mathrm{e}$ & - \\
\hline & $F$ 值 $F$-value & & $121.24^{* *}$ & & $154.35^{* *}$ & \\
\hline \multirow[t]{8}{*}{$2016-2017$} & 倒二叶出生期 & 24 & $23.6 \mathrm{~b}$ & 18.2 & $24.2 \mathrm{~b}$ & 18.3 \\
\hline & $\begin{array}{l}\text { The appearance of the penultimate leaf } \\
\text { stage }\left(5^{\circ} \mathrm{C} /-3^{\circ} \mathrm{C}\right)\end{array}$ & 48 & $25.2 \mathrm{a}$ & 19.8 & $26.6 \mathrm{a}$ & 20.6 \\
\hline & 孕穗期 & 24 & $13.6 \mathrm{~d}$ & 8.2 & $14.6 \mathrm{~d}$ & 8.7 \\
\hline & Booting stage $\left(8^{\circ} \mathrm{C} /-1^{\circ} \mathrm{C}\right)$ & 48 & $15.4 \mathrm{c}$ & 10.0 & $16.8 \mathrm{c}$ & 10.9 \\
\hline & 开花期 & 24 & $7.0 \mathrm{f}$ & 1.6 & $8.0 \mathrm{f}$ & 2.0 \\
\hline & Anthesis stage $\left(12^{\circ} \mathrm{C} / 4^{\circ} \mathrm{C}\right)$ & 48 & $9.8 \mathrm{e}$ & 4.4 & $10.2 \mathrm{e}$ & 4.3 \\
\hline & 自然生长对照 Control & & $5.4 \mathrm{~g}$ & - & $6.0 \mathrm{~g}$ & - \\
\hline & $F$ 值 $F$-value & & $245.51^{* *}$ & & $215.02^{* *}$ & \\
\hline
\end{tabular}

\footnotetext{
**表示极显著差异。方差分析在同一年度内进行, 同列不同字母表示 0.05 水平显著性。
}

${ }^{* *}$ indicates significant differences at $P<0.01$. Different small letters in the same column mean significant differences among treatments for the same year at the 0.05 level. 


\section{2 春季不同时期低温对穗部性状的影响}

倒二叶出生期和孕穗期低温胁迫后, 小麦结实 小穗数和每小穗结实粒数均显著低于自然生长对 照, 且小穗退化百分率随着低温胁迫时间的延长呈 上升趋势(表 2)。在两年间, 扬麦 16 倒二叶出生期 低温处理 $24 \mathrm{~h}$ 和 $48 \mathrm{~h}$ 后平均小穗退化百分率分别 为 $17.9 \%$ 和 $18.7 \%$, 孕穗期低温处理 $24 \mathrm{~h}$ 和 $48 \mathrm{~h}$ 后 平均小穗退化百分率分别为 $14.0 \%$ 和 $16.4 \%$, 开花 期低温处理扬麦 16 退化小穗数略高于自然对照处 理, 但无显著差异; 徐麦 30 在两年间倒二叶出生 期低温处理 $24 \mathrm{~h}$ 和 $48 \mathrm{~h}$ 之后平均小穗退化百分率 分别为 $22.0 \%$ 和 $24.0 \%$, 孕穗期低温处理 $24 \mathrm{~h}$ 和 $48 \mathrm{~h}$ 后平均小穗退化百分率分别为 $19.9 \%$ 和 $21.2 \%$, 徐麦 30 开花期低温处理导致退化小穗数显著高于 对照处理, 说明徐麦 30 在开花期对低温反应更敏 感。2 个品种 3 个时期低温处理后, 每小穗结实粒 数均低于自然生长对照处理, 且随低温处理时间的 延长而减少。相关性分析表明, 2 个品种两年间花粉 败育率与小穗退化数均成显著正相关，2015-2016 年, 扬麦 16 相关系数 $0.935^{* *}$, 徐麦 30 相关系数 $0.780^{*}, 2016-2017$ 年, 扬麦 16 相关系数 $0.848^{*}$, 徐 麦 30 相关系数 $0.980^{* *}$, 退化小穗数随着花粉败育 率的增加呈上升趋势(图 6)。

\section{3 讨论}

\section{1 春季低温对小麦花粉育性的影响}

花药的发育情况直接影响小麦粒数的形成。有 研究表明, 不育小麦的花药异常情况大多出现在小 孢子母细胞期、单核靠边期和二胞花粉期 ${ }^{[22-23]}$, 小 麦剑叶与倒二叶叶耳距为 $0 \sim 4 \mathrm{~cm}$ 时幼穗中小孢子 母细胞处于减数分裂的盛期, 对零度以上低温最为 敏感, 低温导致后期出现落后的染色体、后期或末 期染色体仍停留在赤道板上等异常现象 ${ }^{[24]}$ 。本研究 结果亦表明, 孕穗期低温对 2 个品种小麦花粉母细 胞减数分裂有显著影响, 低温处理后的小麦花粉母 细胞出现染色体配对紊乱、减数分裂染色体不同步、 子细胞差异明显等异常现象。赵莎等 ${ }^{[25]}$ 研究表明, 败育小麦农圼 58 花药的线玷层细胞提前启动细胞 程序性死亡, 但解体过程缓慢, 使单核花粉无法获 得所需的营养物质而败育。温敏核不育小麦花药在 二胞花粉后期, 细胞质中内含物质不持续增加, 淀 粉粒积累终止与花粉败育有关 ${ }^{[20]}$ 。本试验研究结果
表明, 倒二叶出生期和孕穗期低温处理后的花药中, 线玷层在三胞花粉时期仍有较多残留的痕迹, 说明 线毡层没有适时解体，影响了花粉发育过程中营养 物质的供给。同时亦观察到 2 个时期低温处理均降 低了花粉细胞内淀粉粒数量和蛋白质的积累量, 使 得花粉在发育过程中没有充足的养分供应, 不能进 一步发育为成熟的花粉粒。与温敏核不育花粉相比, 本研究中低温处理仅使花粉的内含物质积累量下降, 并没有出现非常严重的空泡化现象, 这也是低温处 理后结实率并没有显著下降的原因。有研究表明, 小麦拔节期、孕穗期低温显著降低叶片的光合能 力 $^{[26-27]}$, 减少植株干物质积累 ${ }^{[28]}$ 。本研究中倒二叶 出生期低温处理对花药中淀粉和蛋白质积累的影响 大于减数分裂期低温, 这可能是由于倒二叶出生期 低温处理对叶片伤害重, 影响了叶片的光合作用, 也间接影响了花粉的营养供给，导致花粉败育率显 著增加; 同一时期随着低温处理时间的延长, 败育 率增高。有研究指出, 冬性小麦低温诱导的抗冻害 基因在从营养生长期转向生殖生长期的过程中表达 量是显著下降的, 遇春季低温抗寒性下降 ${ }^{[29]}$, 本试 验中 2 个品种间徐麦 30 败育率大于扬麦 16 , 这个结 果与每穗结实粒数下降的结果一致, 进一步说明半 冬性品种徐麦 30 在小麦后期低温的敏感性高于春 性品种扬麦 16 。

从花药原基分化到成熟花粉粒形成的过程中, 花粉母细胞减数分裂和花药线毡层正常发育是形成 可育花粉的关键 ${ }^{[30]}$ 。本试验研究结果表明, 孕穗期 低温处理后出现了花粉母细胞减数分裂异常, 花药 细胞畸形以及线延层分解迟缓等现象，花粉育性亦 降低。在拟南芥中 RCK 基因发生突变后同源染色体 联会和交叉紊乱，二价体数目减少，出现单价体， 花粉母细胞减数分裂异常, 导致花粉败育 ${ }^{[31]}$ 。在线 毡层发育的过程中, 多个受体蛋白激酶 ${ }^{[32]}$ 、转录因 子 MYB (v-myb avian myeloblastosis viral oncogene homolog)结构域蛋白 ${ }^{[33]}$ 、锌指蛋白中的 PHD-Finger 结构域蛋白 ${ }^{[34]}$ 等均参与调控, 小麦雄性不育与育性 相关基因表达也有关，早在减数分裂期育性基因的 表达就出现差异，且外界温度对不育基因表达量有 调控作用 ${ }^{[35]}$, 本试验中低温胁迫是否导致基因或者 蛋白调控过程异常, 从而影响花粉母细胞减数分裂 和线毡层的程序性死亡的启动致花粉败育, 尚需从 分子生物学角度开展深入研究。 


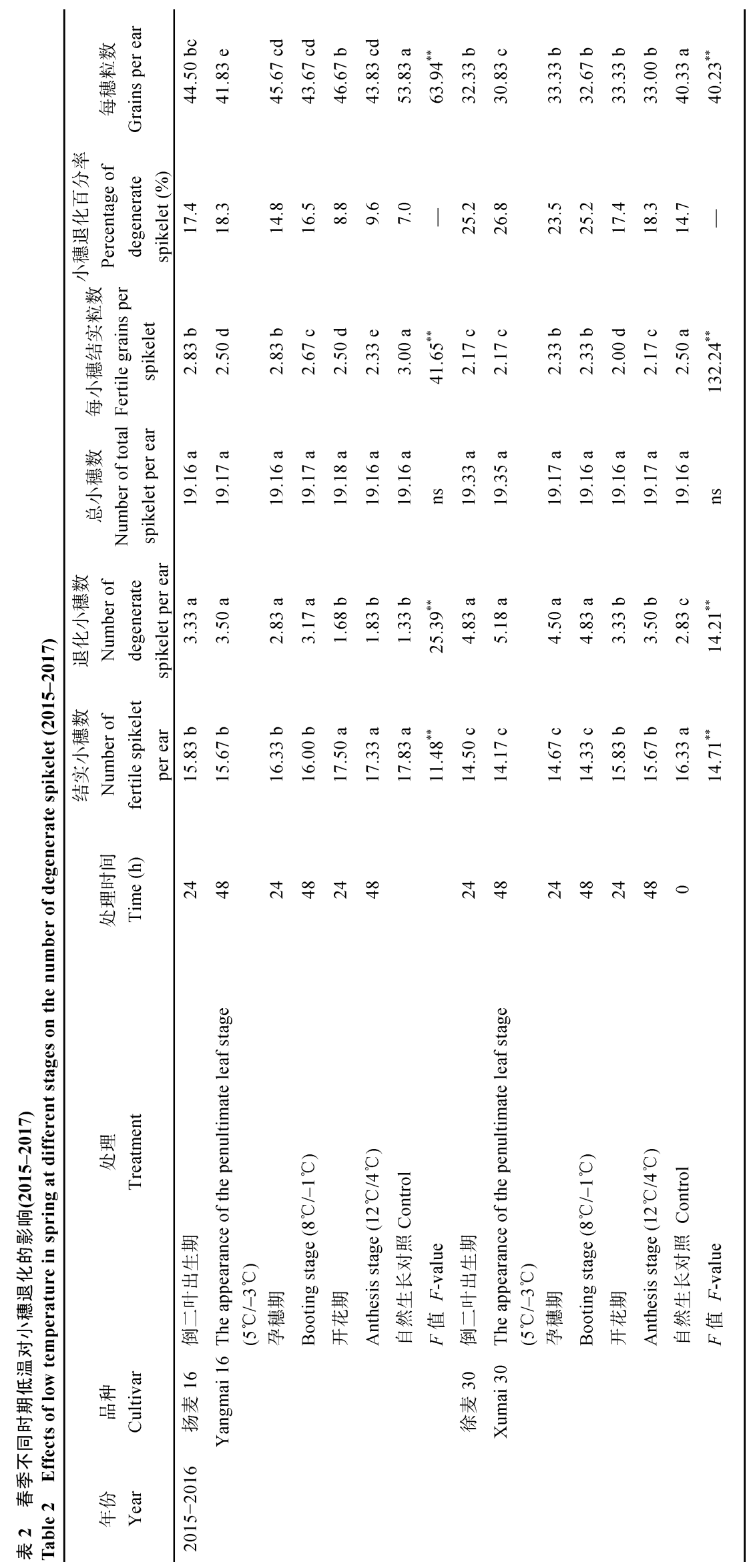




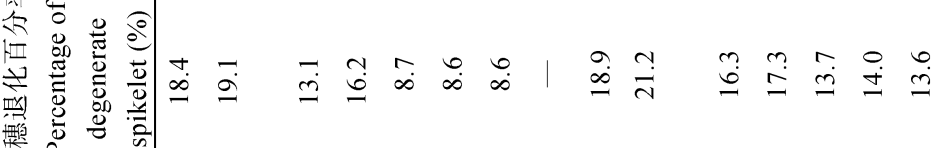
整

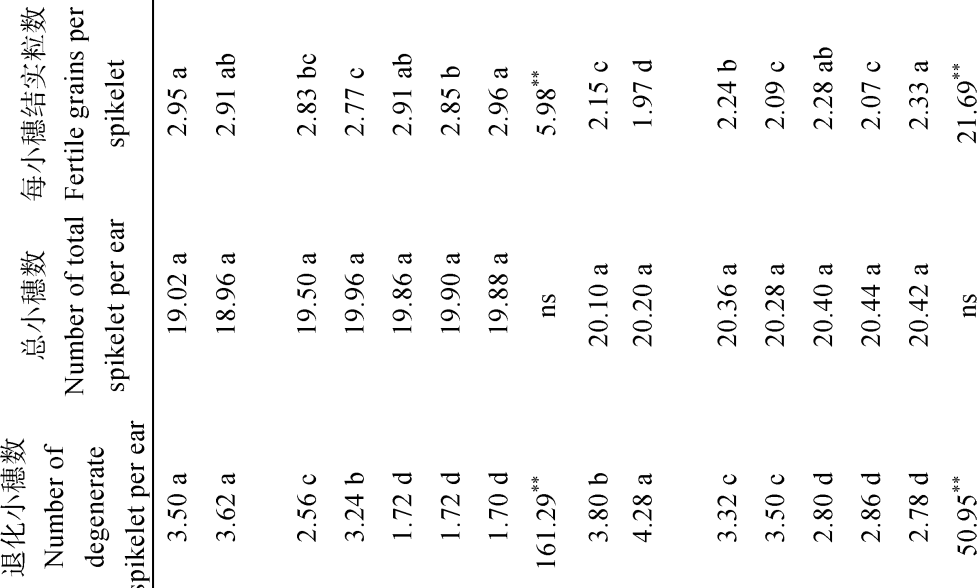

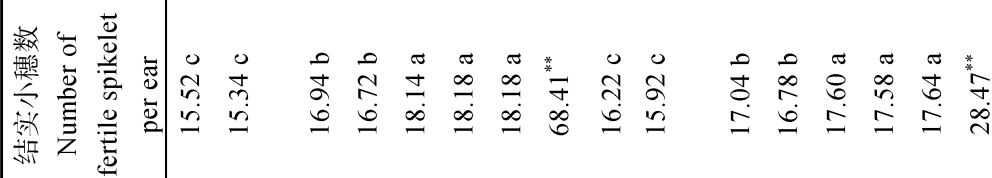
焉亚导

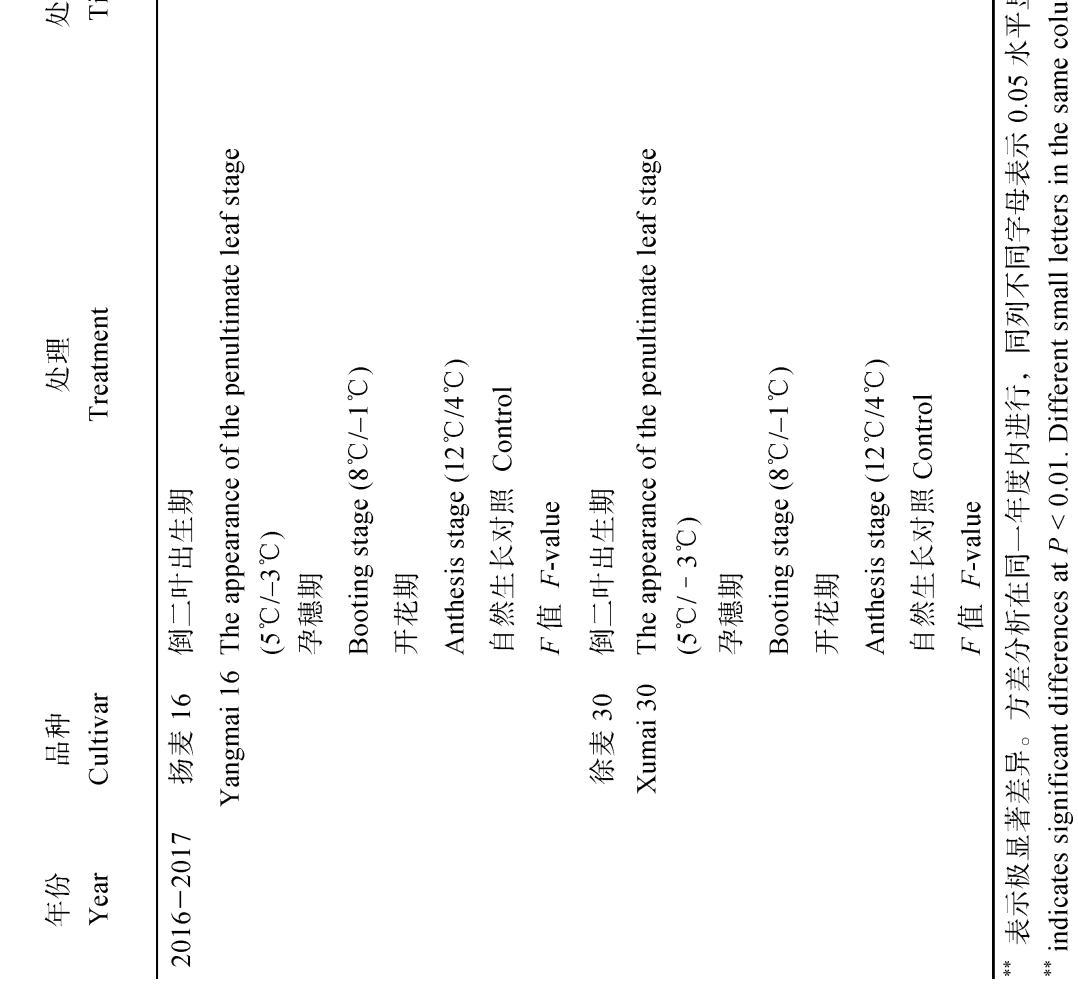




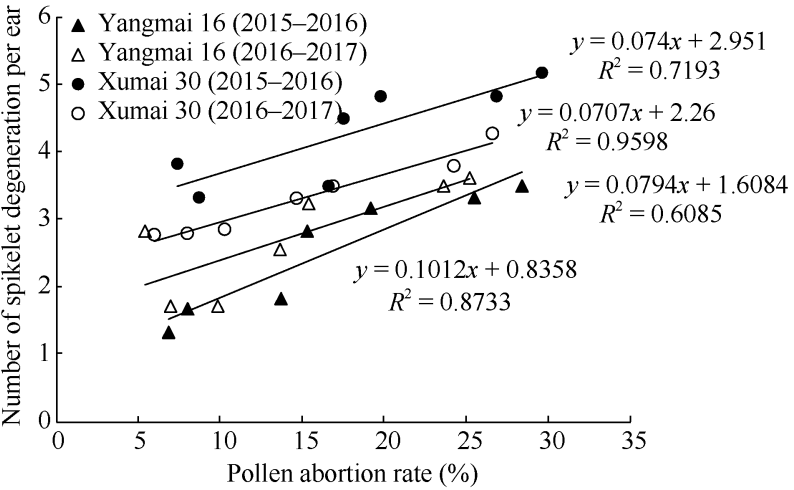

图 6 小麦花粉败育率与退化小穗数的关系

Fig. 6 Relationships of pollen abortion rate and the number of degenerate spikelet

\section{2 春季低温对小麦每穗粒数的影响}

春季低温造成穗数和每穗粒数显著下降 ${ }^{[11,13,36]}$ 。拔 节期和孕穗期低温对穗数和每穗粒数的影响超过对 粒重的影响, 特别是在孕穗期低温处理后每穗粒数 下降达 $55.1 \%$, 是产量降低的主要原因 ${ }^{[37]}$ 。Subedi 等 ${ }^{[38-39]}$ 研究结果表明, 抽穗后低温显著降了小麦结 实率，孕穗至开花期低温导致小麦每穗粒数显著下 降，产量下降了 35\% 78\%。本试验研究结果亦表明， 倒二叶出生期和孕穗期低温均显著降低了小麦结实 小穗数和每穗粒数, 增加了退化小穗数, 且随着低 温时间的延长，小穗退化百分率呈上升趋势，每穗 粒数呈下降趋势。开花期低温略降低了结实小穗数 和每穗粒数。相关分析表明花粉败育率与退化小穗 数呈显著正相关, 这也进一步说明倒二叶出生期和 孕穗期低温引起花粉败育是此期低温致每穗粒数下 降的主要原因。生产中这 2 个生育时期若发生低温 天气值得关注, 后续将开展春季低温的避灾减灾调 控途径研究，以提高小麦抗春季低温逆境能力，实 现稳产增产。

\section{4 结论}

小麦孕穗期低温导致花粉母细胞减数分裂出现 染色体配对紊乱等异常现象, 倒二叶出生期和孕穗 期低温延迟了花药线毡层的降解, 花药中多糖物质 淀粉和蛋白质的积累量下降, 花粉发育因营养物质 不足败育率增加, 开花期低温处理花粉败育率略有 下降。3 个时期低温处理均降低小麦每小穗结实粒 数和每穗粒数, 并随低温处理时间的延长呈上升趋 势, 以倒二叶出生期低温处理穗粒数降低的幅度最 大, 其次是孕穗期, 开花期穗粒数降低幅度最小。相
关分析表明，春季低温导致小麦花粉育性下降是每 穗粒数降低的主要生理原因。

\section{References}

[1] Augspurger C K. Reconstructing patterns of temperature, phenology, and frost damage over 124 years: spring damage risk is increasing. Ecology, 2013, 94: 41-50.

[2] Zheng B Y, Chapman S C, Christopher J T, Frederiks T M, Chenu K. Frost trends and their estimated impact on yield in the Australian wheat belt. $J$ Exp Bot, 2015, 66: 3611-3623.

[3] Barlow K M, Christy B P, O’Leary G J, Riffkin P A, Nuttall J G. Simulating the impact of extreme heat and frost events on wheat crop production: a review. Field Crops Res, 2015, 171: 109-119.

[4] 罗新兰, 张彦, 孙忠富, 杜克明, 宋广树. 黄淮平原小麦霜冻 害时空分布特点的研究. 中国农学通报, 2011, 27(18): 45-50.

Luo X L, Zhang Y, Sun Z F, Du K M, Song G S. Spatial and temperature distribution of winter wheat frost injury in Huanghuai plain. Chin Agric Sci Bull, 2011, 27(18): 45-50 (in Chinese with English abstract).

[5] 张永阁. 柘城县小麦冻害发生原因及防治措施. 河南农业, 2016, (1): 45.

Zhang Y G. Reasons and protective measures of wheat frost damage in Zhecheng. Henan Agron, 2016, (1): 45 (in Chinese).

[6] 赵刚, 申双和, 褚荣浩. 江苏省倒春寒发生程度评估. 江苏农 业科学, 2018, 46(6): 243-247.

Zhao G, Shen S H, Chu R H. Assessment of the incidence of cold spring in Jiangsu. Jiangsu Agric Sci, 2018, 46 (6): 243-247 (in Chinese).

[7] 王葳葳, 刘君圣, 徐迎菊. 2013 年春季霜冻对兴化市冬小麦生 长的影响及应对补救措施. 现代农业科技, 2014, (16): 225-226.

Wang W W, Liu J S, Xu Y J. Effect of spring frost on the growth of winter wheat and remedial techniques in Xinghua in 2013. Morden Agric Sci Tech, 2014, (16): 225-226 (in Chinese).

[8] 蔡剑, 姜东. 气候变化对中国冬小麦生产的影响. 农业环境科 学学报, 2011, 30: 1726-1733.

Cai J, Jiang D. The effect of climate change on winter wheat production in China. J Agro-Environ Sci, 2011, 30: 1726-1733 (in Chinese with English abstract).

[9] 冯伟森, 张学品, 吴少辉, 高海涛, 张灿军. 不同播期对洛旱 7 号小麦幼穗分化及产量的影响. 河南农业科学, 2011，40(10): 32-34.

Feng W S, Zhang X P, Wu S H, Gao H T, Zhang C J. Effects of different sowing dates on spike characteristics and yield of Luohan 7. J Henan Agric Sci, 2011, 40(10): 32-34 (in Chinese with English abstract).

[10] 李春燕, 徐雯, 刘立伟, 雷晓伟, 杨景, 周冬冬, 朱新开, 郭文 善. 药隔至开花期低温对小麦产量和生理特性的影响. 麦类 作物学报, 2016, 36(1): 77-85.

Li C Y, Xu W, Liu L W, Lei X W, Yang J, Zhou D D, Zhu X K, Guo W S. Effect of short-time low temperature from anther connective stage to anthesis on wheat yield and physiological characteristics. J Triticeae Crops, 2016, 36(1): 77-85 (in Chinese with English abstract).

[11] 张自阳, 王智煜, 王斌, 王志伟, 朱启迪, 霍云风, 茹振钢, 刘 
明久. 春季穗分化阶段低温处理对不同小麦品种幼穗结实性 及生理特性的影响. 华北农学报, 2019, 34(4): 130-139.

Zhang Z Y, Wang Z Y, Wang B, Wang Z W, Zhu Q D, Huo Y F, $\mathrm{Ru} Z \mathrm{G}$, Liu M J. Effects of low temperature treatment at spring spike differentiation stage on young ear fruiting and physiological characteristics of different wheat varieties. Acta Agric Boreali Sin, 2019, 34(4): 130-139 (in Chinese with English abstract).

[12] Thakur P, Kumar S, Malik J A, Berger J D, Nayyar H. Cold stress effects on reproductive development in grain crops: an overview. Environ Exp Bot, 2010, 67: 429-443.

[13] 王亚梁, 张玉屏, 朱德峰, 向镜, 武辉, 陈惠哲, 张义凯. 水稻 穗分化期高温胁迫对颖花退化及籽粒充实的影响. 作物学报, 2016, 42: 1402-1410.

Wang Y L, Zhang Y P, Zhu D F, Xiang J, Wu H, Chen H Z, Zhang Y K. Effect of heat stress on spikelet degeneration and grain filling at panicle initiation period of rice. Acta Agron Sin, 2016, 42: 1402-1410 (in Chinese with English abstract).

[14] 王俊生, 张改生, 原蕾, 张明珠, 牛娜, 马守才, 叶景秀. 化学 杂交剂诱导的小麦生理型雄性不育花药的活性氧代谢. 西北 植物学报, 2009, 29: 1351-1357.

Wang J S, Zhang G S, Yuan L, Zhang M Z, Niu N, Ma S C, Ye J $\mathrm{X}$. Metabolism of reactive oxygen species of physiological male-sterile anther induced by chemical hybrid agent in wheat. Acta Bot Boreali-Occident Sin, 2009, 29: 1351-1357 (in Chinese with English abstract).

[15] 蒙立颖, 石晓艺, 胡甘, 齐智, 宋喜悦. $\mathrm{K}$ 型温敏雄性不育小麦 KTM3315A 的鉴定及花粉败育特点的初步分析. 中国农业大 学学报, 2015, 20(5): 1-8.

Meng L Y, Shi X Y, Hu G, Qi Z, Song X Y. Identification and characteristics of KTM3315A, a thermos-sensitive male sterile line with Aegilops kotschyi cytoplasm. J China Agric Univ, 2015, 20(5): 1-8 (in Chinese with English abstract).

[16] 马翎健, 司美茹, 宋喜悦, 胡银刚, 奚亚军, 何蓓如, 刘曙东. 牡山羊草细胞质小麦核代换系酶活性及其与花粉败育的关系. 麦类作物学报, 2001, 21(3): 35-37.

Ma L J, Si M R, Song X Y, Hu Y G, Xi Y J, He P R, Liu S D. Relationship between microspore abortion and activities of superoxide dismutase (SOD) and catalase (CAT) of wheat nuclear sustitutional lines in Ae. juvenalis cytoplasm. $J$ Triticeae Crops, 2001, 21(3): 35-37 (in Chinese with English abstract).

[17] 巨岗, 朱启迪, 张改生, 张姣, 于永昂, 刘红占, 牛娜, 王军卫. 小麦生理型雄性不育系中天冬氨酸蛋白酶与线玷层代谢的相 关性分析. 核农学报, 2018, 32: 430-437.

Ju L, Zhu Q D, Zhang G S, Zhang J, Yu Y A, Liu H Z, Niu N, Wang J W. The research on the correlation between aspartic proteinase and anther tapetum in physiological male sterility wheat. J Nucl Agric Sci, 2018, 32: 430-437 (in Chinese with English abstract).

[18] 张艳, 何勇, 李建雄, 田志宏. 线毛层发育和激素对拟南芥育 性的影响. 安徽农学通报, 2017, 23(6): 34-38.

Zhang Y, He Y, Li J X, Tian Z H. Effects of tapetal development and hormones on fertility of arabidopsis thaliana. Anhui Agric Sci Bull, 2017, 23(6): 34-38 (in Chinese with English abstract).

[19] 宋国琦, 胡银岗, 林凡云, 董普辉, 马翎健, 宋喜悦, 何蓓如. YS 型小麦温敏雄性不育系A3017 控温条件下的花粉育性比较. 麦类作物学报, 2006, 26(1): 17-20.
Song G Q, Hu Y G, Lin F Y, Dong P H, Ma L J, Song X Y, He B R. Comparison on the pollen fertility of YS type thermo-sensitive male-sterile wheat line A3017 under artificial temperature conditions. J Triticeae Crops, 2006, 26(1): 17-20 (in Chinese with English abstract).

[20] 李东霄, 李淦, 冯素伟, 茹振钢. 温敏核不育小麦可育和不育 花药的细胞化学观察. 作物学报, 2013, 39: 878-884.

Li D X, Li G, Feng S W, Ru Z G. Cytochemical observation of fertile and sterile anthers of thermo-sensitive genic male-sterile wheat. Acta Agron Sin, 2013, 39: 878-884 (in Chinese with English abstract).

[21] 李东霄, 邓小莉, 冯素伟, 徐龙龙, 茹振钢. 温敏核不育小麦 可育和败育花粉的超微结构观察. 中国细胞生物学学报, 2013, 35: 1119-1125.

Li D X, Deng X L, Feng S W, Xu L L, Ru Z G. Ultrastructural observation of fertile and sterile pollen grains of a thermo-sensitive genic male-sterile wheat. Chin J Cell Biol, 2013, 35: 1119-1125 (in Chinese with English abstract).

[22] 刘海英, 甄俊琦, 胡铁柱, 茹振钢, 李珍, 胡雪寒, 邢晨涛, 高 远. 小麦温敏雄性不育系 BNS366 小狍子发育和花粉育性检 测方法研究. 麦类作物学报, 2018, 38: 379-385.

Liu H Y, Zhen J Q, Hu T Z, Ru Z G, Li Z, Hu X H, Xing C T, Gao Y. Study on microspore development and pollen fertility detection of thermos-sensitive male-sterile wheat line BNS366. J Triticeae Crops, 2018, 38: 379-385 (in Chinese with English abstract).

[23] 韩笑冰, 利容千, 徐乃瑜, 王建波, 徐祖元. 小麦不同胞质不 育系花粉败育的细胞学比较研究. 作物学报, 1996, 22: 646-651.

Han X B, Li R Q, Xu N Y, Wang J B, Xu Z Y. A comparative cytological study on the pollen abortion of different cytoplasmic male sterile lines of wheat. Acta Agron Sin, 1996, 22: 646-651 (in Chinese with English abstract).

[24] Barton D A, Cantrill L C, Law A M K, Phillips C G, Sutton B G, Overall R L. Chilling to zero degrees disrupts pollen formation but not meiotic microtubule arrays in Triticum aestivum L. Plant Cell Environ, 2014, 37: 2781-2794.

[25] 赵莎, 姚家玲. 光敏核不育水稻花粉发育的细胞学研究与 PCD 检测. 华中农业大学学报, 2007, 26: 283-288.

Zhao S, Yao J L. Cytological study and PCD assay on pollen development of photoperiod sensitive genic male sterile rice. $J$ Huazhong Agric Univ, 2007, 26: 283-288 (in Chinese with English abstract).

[26] 王瑞霞, 问长生, 张秀英, 孙果忠, 钱兆国, 元晓蕾, 牟秋焕, 肖世和. 春季低温对小麦产量和光合特性的影响. 作物学报, 2018, 44: 288-296.

Wang R X, Yan C S, Zhang X Y, Sun G Z, Qian Z G, Qi X L, Mou Q H, Xiao S H. Effect of low temperature in spring on yield and photosynthetic characteristics of wheat. Acta Agron Sin, 2018, 44: 288-296 (in Chinese with English abstract).

[27] Li X N, Pu H C, Liu F L, Zhou Q, Cai J, Dai T B, Cao W X, Jiang D. Winter wheat photosynthesis and grain yield responses to spring freeze. Agron J, 2015, 107: 1002-1010.

[28] Liu L L, Ji H T, An J P, Shi K J, Ma J F, Liu B, Tang L, Cao W X, Zhu Y. Response of biomass accumulation in wheat to low-temperature stress at jointing and booting stages. Environ Exp Bot, 2019, 157: 46-57. 
[29] Prášil I T, Prášilová P, Pánková K. The relationship between vernalization requirement and frost tolerance in substitution lines of wheat. Biol Plant, 2005, 49: 195-200.

[30] 刘伟华, 邱博, 罗红兵. 花药线毛云发育和花粉母细胞减数分 裂相关基因研究进展. 作物研究, 2015, 29: 311-316.

Liu W H, Qiu B, Luo H B. Advances in genes related to tapetum development and microsporocyte meiosis in anther. Crop Res, 2015, 29: 311-316 (in Chinese with English abstract).

[31] Chen C B, Zhang W, Timofejeva L, Gerardin Y, Ma H. The arabidopsis ROCK-N-ROLLERS gene encodes a homolog of the yeast ATP-dependent DNA helicase MER3 and is required for normal meiotic crossover formation. Plant J, 2005, 43: 321-334.

[32] Johnson K L, Ingram G C. Sending the right signals: regulating receptor kinase activity. Curr Opin Plant Biol, 2005, 8: 648-656.

[33] Stracke R, Werber M, Weisshaar B. The $R 2 R 3-M \gamma B$ gene family in Arabidopsis thaliana. Curr Opin Plant Biol, 2001, 4: 447-456.

[34] Ito T, Shinozaki K. The MALE STERILITY1 gene of Arabidopsis, encoding a nuclear protein with a PHD-finger motif, is expressed in tapetal cells and is required for pollen maturation. Plant Cell Physiol, 2002, 43: 1285-1292.

[35] 刘菲, 马晓飞, 李艳飞, 王爱芳, 靳凤, 马翎健. 两个育性相
关基因在几类小麦雄性不育材料中的表达研究. 西北植物学 报, 2012, 32: 1731-1735.

Liu F, Ma X F, Li Y F, Wang A F, Jin F, Ma L J. Expression analysis of two genes related to male fertility in a few types of male sterile wheat. Acta Bot Boreali-Occident Sin, 2012, 32: 1731-1735 (in Chinese with English abstract).

[36] Zhang W J, Wang J Q, Huang Z L, Mi L, Xu K F, Wu J J, Fan Y H, Ma S Y, Jiang D G. Effects of low temperature at booting stage on sucrose metabolism and endogenous hormone contents in winter wheat spikelet. Front Plant Sci, 2019, 10: 498.

[37] Ji H T, Xiao L J, Xia Y M, Song H, Liu B, Tang L, Cao W X, Zhu Y, Liu L L. Effects of jointing and booting low temperature stresses on grain yield and yield components in wheat. Agric ForMeteorol, 2017, 243: 33-42.

[38] Subedi K D, Gregory P J, Summerfield R J. Gooding M J. Cold temperatures and boron deficiency caused grain set failure in spring wheat (Triticum aestivum L.). Field Crops Res, 1998, 57: 277-288.

[39] Subedi K D, Gooding M J, Gregory P J. Cultivar variation in boron accumulation and grain set in wheat under the influence of cold temperature. Ann Appl Biol, 2001, 138: 97-101. 